\title{
Formation of air clathrate hydrates in polar ice sheets: heterogeneous nucleation induced by micro-inclusions
}

\author{
Hiroshi OHNO, ${ }^{1 *}$ Vladimir Ya. LIPENKOV, ${ }^{2}$ Takeo $\mathrm{HONDOH}^{1}$ \\ ${ }^{1}$ Institute of Low Temperature Science, Hokkaido University, Sapporo 060-0819, Japan \\ E-mail: hiroshi-ohno@aist.go.jp \\ ${ }^{2}$ Arctic and Antarctic Research Institute, 199397 St Petersburg, Russia
}

\begin{abstract}
To investigate factors influencing nucleation of air clathrate hydrates in polar ice sheets, we have performed high-resolution mapping of the distributions of soluble impurities, air bubbles and airhydrate crystals versus depth in the Dome Fuji Antarctic ice. Significant correlation observed between the concentrations of air inclusions and impurities in ice along with frequent occurrence of impurities inside hydrate crystals suggest that micro-inclusions promote hydrate nucleation in the ice matrix. Our observations also show that the diffusive macroscopic-scale redistribution of air constituents in ice in the bubble-hydrate transition zone is controlled by the original sedimentary layering of soluble impurities acting as nucleation helpers. The results of this study are important for the correct interpretation of high-resolution gas analyses of ice cores and for better understanding the global bubble-to-hydrate transformation process in polar ice sheets.
\end{abstract}

\section{INTRODUCTION}

Air bubbles and air hydrates (hereafter air inclusions) in polar ice cores attract considerable interest as important proxies for past climate changes: their air provides the most direct record of past atmospheric gas compositions (e.g. Kawamura and others, 2007; Lüthi and others, 2008), and their mean size and number concentration exhibit significant variations depending on the temperature and accumulation rate prevailing during the snow-ice transformation (Barkov and Lipenkov, 1984; Uchida and others, 1994a; Narita and others, 1999; Pauer and others, 1999; Lipenkov, 2000).

Understanding the mechanism of air-bubble to clathratehydrate transformation in ice sheets is essential for proper interpretation of ice-core records, because the processes of air clathration can alter the climate signals. Although considerable knowledge of post-nucleation hydrate growth has been accumulated through previous experimental (Uchida and others, 1992, 1994b) and theoretical work (Salamatin and others, 1998, 2003), little is known about hydrate nucleation phenomena. Since there are abundant hydrate guest molecules in air bubbles, it is generally thought that air hydrate will always nucleate at a bubble-ice interface (Hondoh and Uchida, 1992). In contrast to this common view, we have previously suggested that a significant number of hydrate crystals may nucleate heterogeneously in the ice matrix away from air bubbles (Ohno and others, 2004). In the present study, we analyze the spatial distributions of both types of air inclusions and impurities in the Dome Fuji Antarctic ice core to provide new evidence that heterogeneous nucleation is induced by the presence of micro-inclusions.

\section{METHOD AND RESULTS}

We have mapped the spatial distributions of air inclusions and impurities in two $17 \mathrm{~cm}$ long ice cores from depths of 999.34-999.51 and 999.57-999.74 m, i.e. from near the middle of the bubble-to-hydrate transition zone. The

*Present address: Methane Hydrate Research Laboratory, National Institute of Advanced Industrial Science and Technology, Sapporo 062-8517, Japan. bubble-to-hydrate transition in the Dome Fuji ice core occurs at $\sim 500-1200 \mathrm{~m}$ depth (Narita and others, 1999), corresponding to $\sim 18.3-76.8 \mathrm{kaBP}$, the last glacial period (Hondoh and others, 2002). The number concentrations of air- and micro-inclusions in the ice cores were measured continuously with an optical microscope along the core axis in every $1 \mathrm{~cm}$ thick layer. To obtain the average number concentrations of air bubbles, $N_{b}$, clathrate hydrates, $N_{h}$, and micro-inclusions, $N_{\mathrm{m}}$ in an ice layer, we randomly selected 20 cells of dimension $1.8 \times 1.4 \times 5 \mathrm{~mm}^{3}$ for air inclusions, and 20 regions of $0.18 \times 0.14 \times 5 \mathrm{~mm}^{3}$ for micro-inclusions. We then counted the number of inclusions in each cell. The standard errors of $N_{b}, N_{h}$ and $N_{m}$ were about $9 \%, 12 \%$ and $17 \%$, respectively. For the same samples, soluble ion content was measured using ion chromatography. Detailed information on the soluble-ion analysis is presented by Igarashi and others (1998). In addition, using the same experimental technique as above, we obtained the average number concentrations of inclusions and determined the location of micro-inclusions with respect to hydrate crystals in three vertical ice sections $\left(8 \times 5 \times 0.5 \mathrm{~cm}^{3}\right)$ from depths of 595,751 and $999 \mathrm{~m}$. In these ice sections we also measured the size of 100 clathrate hydrates and counted the number of microinclusions within the hydrates. For the hydrate volume estimation, either a spherical or a cylindrical visual approximation of the inclusion (depending on its shape) was used (Lipenkov, 2000). Detailed information on the Dome Fuji ice core has been published by the Dome-F Deep Coring Group (1998).

The $1 \mathrm{~cm}$ resolution depth profiles of soluble ion concentrations and the number concentrations of air bubbles, clathrate hydrates and micro-inclusions in the $17 \mathrm{~cm}$ long cores are shown in Figure 1. The ratio of the number of hydrates to the total air inclusions, $N_{h} / N$, is also presented in Figure 1 as an index of the degree of transformation from bubbles to hydrates. In spite of the similar temperature and pressure histories of all $1 \mathrm{~cm}$ layers studied, the $N_{h} / N$ varies significantly with depth, ranging between 0.44 and 0.84 . This supports the heterogeneous hydrate nucleation in ice suggested previously (Ohno and others, 2004). The layers 


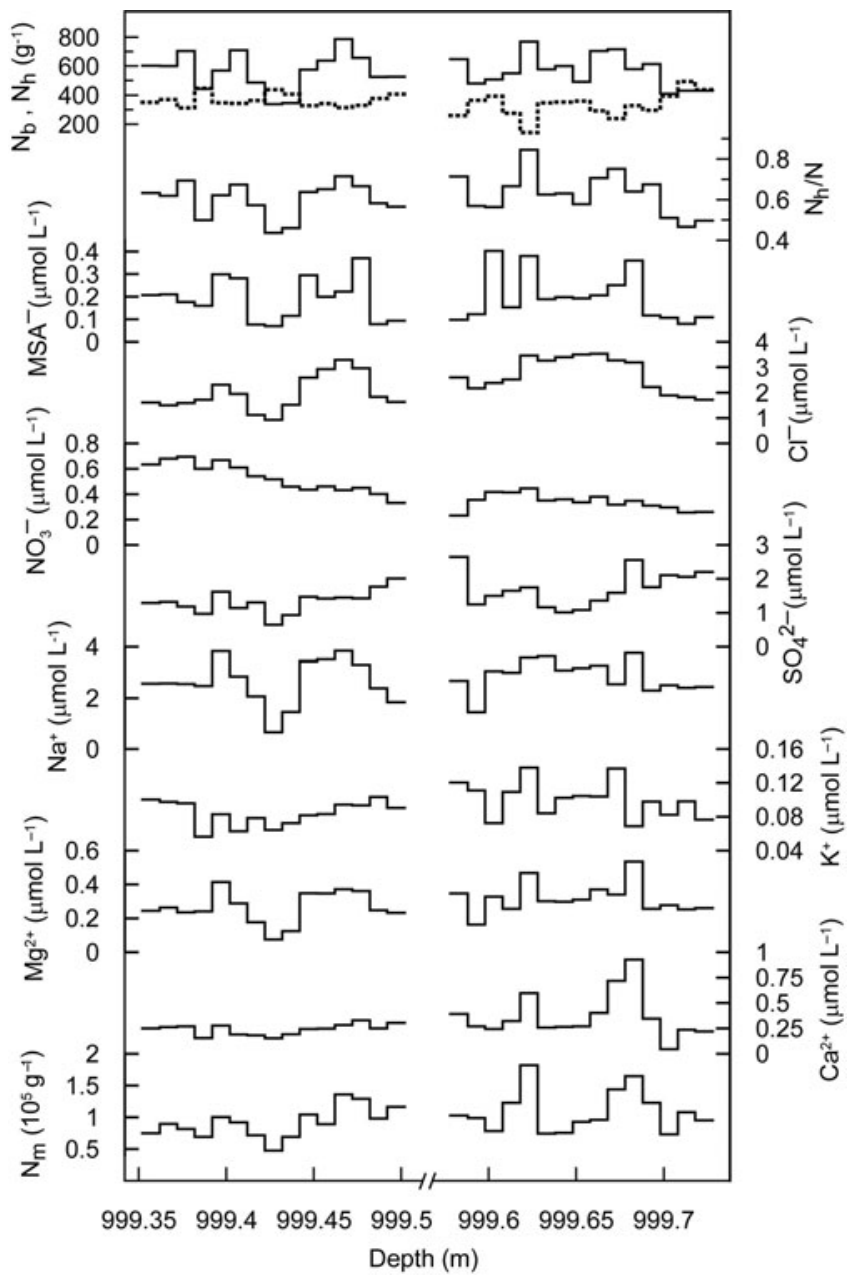

Fig. 1. Depth profiles of soluble ion concentrations and the number concentrations of air bubbles, $N_{b}$ (dotted curve), clathrate hydrates, $N_{\mathrm{h}}$ (solid curve), and micro-inclusions, $N_{\mathrm{m}}$, in the Dome Fuji ice from the bubble-to-hydrate transition zone. The ratio of the number of clathrate hydrates to the total air inclusion number, $N_{h} / N$, can be considered an index of the degree of transformation from bubbles to hydrates.

with higher values of $N_{h} / N$, as a rule, reveal higher ion concentrations and are characterized by higher $N_{m}$ values. This finding is consistent with the in situ observations of bubble-to-hydrate conversion in polar ice samples under high hydrostatic pressure, showing that the hydrate nucleation rate is higher in the samples with greater soluble impurity content (Shimada and Hondoh, 2004). Figure 2 shows empirical relations observed between $N_{h} / N$ and the soluble ion concentrations and between $N_{\mathrm{h}} / N$ and $N_{\mathrm{m}}$. The strongest correlations $\left(R^{2}=0.43\right)$ were found between $N_{\mathrm{h}} / N$ and $\mathrm{Mg}^{2+}$ and between $\mathrm{N}_{\mathrm{h}} / \mathrm{N}$ and $\mathrm{N}_{\mathrm{m}}$. Correlations between $\mathrm{N}_{\mathrm{h}} / \mathrm{N}$ and $\mathrm{Cl}^{-}, \mathrm{Na}^{+}$and $\mathrm{K}^{+}$were relatively strong. Microinclusions consist mainly of water-soluble salts, and most of the water-soluble impurities are confined as salt inclusions (Ohno and others, 2004). Therefore, these results indicate that micro-inclusions induce the hydrate nucleation.

Consistent with the above observation, micro-inclusions were frequently observed inside hydrates. Typical Raman spectra of micro-inclusions inside air hydrates are shown in Figure 3. Table 1 gives the results of statistical analyses of the microscopic observations. The number of micro-inclusions inside hydrates, $N_{\mathrm{m}}{ }^{\prime}$, was considerably higher than that in the ice matrix, $N_{m}$, at all depths under consideration. The
Table 1. Statistical analyses of the location of micro-inclusions with respect to clathrate hydrates in the bubble-to-hydrate transition zone of the Dome Fuji ice. $N_{m}$ and $N_{m}$ ' are the number concentrations of micro-inclusions in the ice matrix and clathrate hydrates, respectively. $N_{h}{ }^{\prime} / N_{h}$ represents the percentage of clathrate hydrates in which at least one micro-inclusion was observed. Values in parentheses show the calculations assuming that micro-inclusions are uniformly distributed in the ice matrix. $N_{\mathrm{m}}{ }^{\prime}$ was estimated from the size measurement of 100 clathrate hydrates measured for a given ice section and the number of micro-inclusions in the hydrates. Age estimations are from Hondoh and others (2002)

\begin{tabular}{lcccrc}
\hline $\begin{array}{l}\text { Depth } \\
\mathrm{m}\end{array}$ & $\begin{array}{c}\text { Age } \\
\mathrm{ka}\end{array}$ & $\begin{array}{c}\mathrm{N}_{\mathrm{m}} \\
\mathrm{cm}^{-3}\end{array}$ & $\begin{array}{c}\mathrm{N}_{\mathrm{m}}{ }^{\prime} \\
\mathrm{cm}^{-3}\end{array}$ & $N_{\mathrm{m}}{ }^{\prime} / \mathrm{N}_{\mathrm{m}}$ & $\begin{array}{c}\mathrm{N}_{\mathrm{h}}{ }^{\prime} / \mathrm{N}_{\mathrm{h}} \\
\%\end{array}$ \\
\hline 595 & 26.2 & $2.2 \times 10^{5}$ & $7.1 \times 10^{7}$ & 320 & $64(0.6)$ \\
751 & 38.6 & $8.1 \times 10^{4}$ & $1.3 \times 10^{7}$ & 155 & $73(1.4)$ \\
999 & 57.7 & $1.2 \times 10^{5}$ & $6.5 \times 10^{6}$ & 53 & $73(5.7)$ \\
\hline
\end{tabular}

micro-inclusions were found in approximately $70 \%$ of hydrates. This is significantly higher than the estimate of $N_{\mathrm{h}}{ }^{\prime} / N_{\mathrm{h}}$ obtained assuming micro-inclusions are uniformly distributed in the ice matrix (values in parentheses in Table 1). These findings strongly support the idea that the clathration is induced by micro-inclusions.

\section{DISCUSSION}

As could be predicted from previous studies (Ohno and others, 2004; Shimada and Hondoh, 2004), the presence of impurities in clathrate hydrates was observed. The evidence presented above indicates that micro-inclusions are the hydrate nucleation promoters. We can now explain the considerable macroscale redistribution of air inclusions in terms of their number and volume, which has been observed previously in the bubble-to-hydrate transition zone of the Dome Fuji core by Ohno and others (2004), as follows. Though the bubble pressure reaches the dissociation pressure of air hydrates at a certain depth $(\sim 400 \mathrm{~m}$ at Dome Fuji), hydrates cannot start to nucleate at bubble walls spontaneously (Hondoh and Uchida, 1992), so air dissolved in the ice matrix becomes supersaturated. The supersaturation increases proportionally with increasing bubble pressure at greater depths, and finally hydrates start to nucleate on micro-inclusions by enclathrating the dissolved air. Though most air bubbles are located on grain boundaries at the beginning of the transition zone (500-750 m) (Ohno and others, 2004), micro-inclusions mostly reside within ice grains and have relatively non-uniform spatial distribution (Ohno and others, 2005). Therefore, tiny hydrate crystals nucleated on micro-inclusions appear inside ice grains, sometimes as groups, as reported by Kipfstuhl and others (2001) and Ohno and others (2004).

Assuming the heterogeneous hydrate nucleation on micro-inclusions outside air bubbles, we can now explain why hydrate crystals at the beginning of the transition zone (500-750 m) are already significantly enriched with oxygen. The difference in gas concentrations between the icebubble and ice-hydrate interfaces causes selective gas fluxes from bubble to hydrate (Ikeda and others, 1999). Since the diffusion of $\mathrm{O}_{2}$ is faster than that of $\mathrm{N}_{2}$ (Ikeda and others, 1999) and air occluded in hydrates formed outside the 

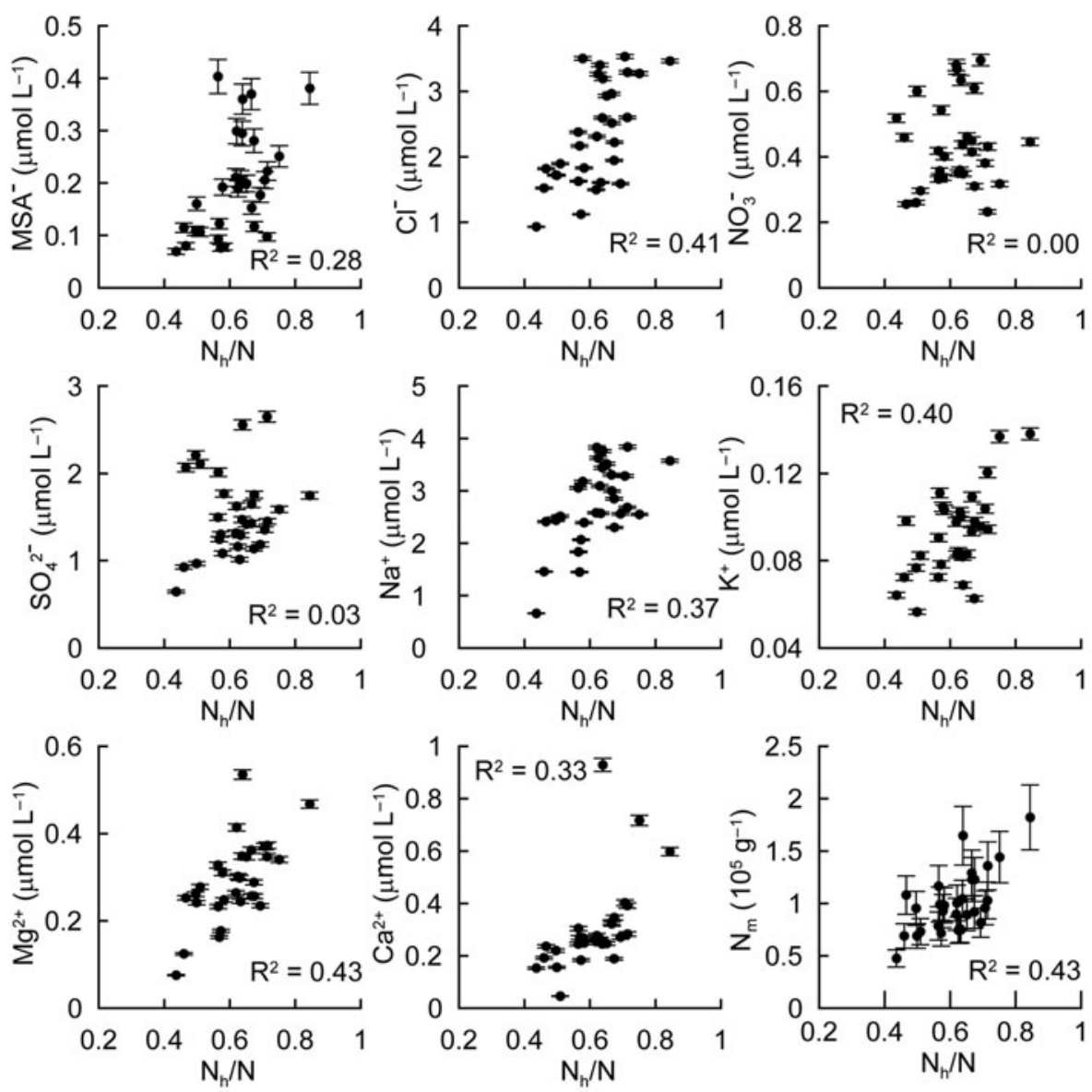

Fig. 2. Correlations between the ratio of the number of clathrate hydrates to the total air inclusion number, $N_{h} / N$, and the soluble ion concentrations, and the number concentration of micro-inclusions, $N_{\mathrm{m}}$.

bubbles is entirely sourced from the diffusion process, the hydrates must have relatively low $\mathrm{N}_{2} / \mathrm{O}_{2}$ values at the start of hydrate formation as reported by Ikeda and others (1999) and Ikeda-Fukazawa and others (2001).

Interestingly, $N_{m}{ }^{\prime} / N_{m}$ decreases significantly with depth (Table 1), indicating active crystal growth after the hydrate nucleation, due to the selective air diffusion from bubbles to hydrates. This observation supports the suggestion (Ohno and others, 2004) that the mass transfer between inclusions by the diffusion through the ice matrix results in considerable changes in volume concentrations of air inclusion observed in the transition zone.

Though $N_{m}{ }^{\prime}$ is significantly higher than $N_{m}$ (Table 1 ), the number of micro-inclusions in clathrate hydrates accounts for $<2 \%$ of the total number of micro-inclusions in the ice matrix (the percentage was estimated from $N_{\mathrm{m}}, N_{\mathrm{m}}{ }^{\prime}$ and the volume fraction of hydrates in the ice matrix), indicating that only part of the micro-inclusions contribute to hydrate nucleation. The distribution of air inclusions in the transition zone suggests that the heterogeneous hydrate nucleation outside air bubbles occurs mainly at the beginning of bubble-to-hydrate transformation (500-750 m; Ohno and others, 2004). We consider that the gas supersaturation in the ice matrix decreases to a level insufficient for heterogeneous nucleation outside air bubbles after the initial hydrate crystals have formed, so further nucleation away from air bubbles will not occur in the remaining stage of the transition.

Micro-inclusions may also help hydrates to nucleate at bubble walls. As shown by Ohno and others (2004), most air
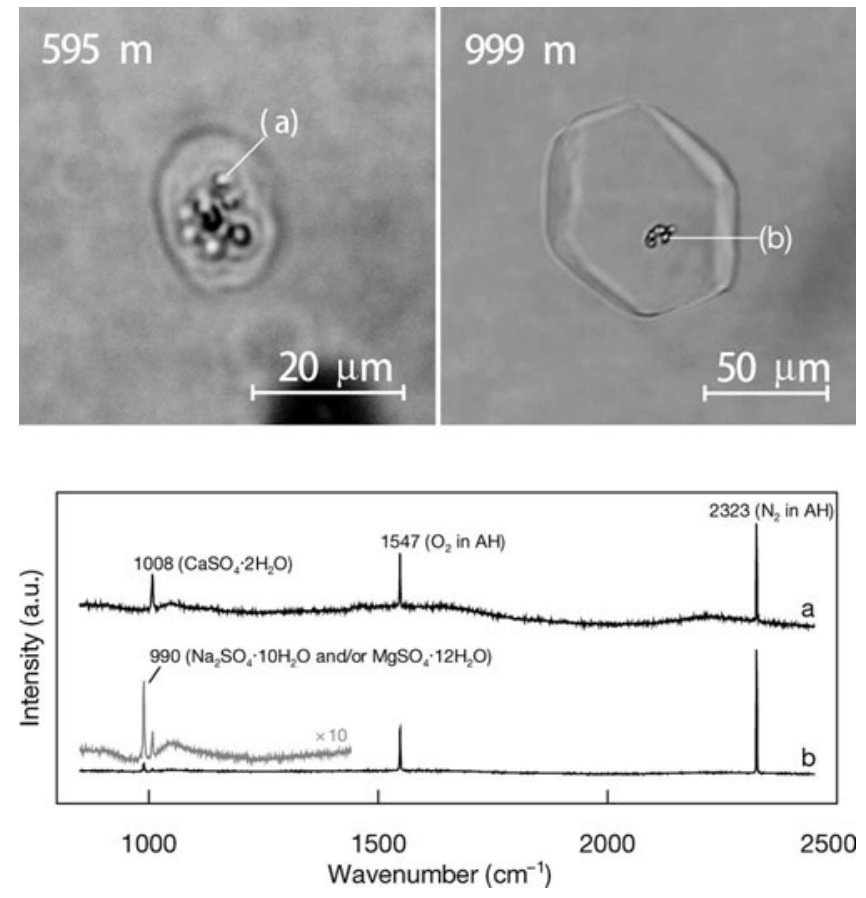

Fig. 3. Micro-inclusions inside hydrate crystals found in the Dome Fuji ice from the bubble-to-hydrate transition zone and their Raman spectra. Raman peak assignments are based on Nakahara and others (1988) and Ohno and others (2005). Detailed information on the Raman measurement is described elsewhere (Ohno and others, 2005). 
bubbles were observed on the ice grain boundaries at the beginning of the transition zone, despite the migration of the boundaries due to ice grain growth. This means that bubbles can migrate with the grain boundaries (the mechanism of this phenomenon is described in Alley and others, 1986). When bubbles collide with micro-inclusions in the course of the migration, the hydration may start on the inclusions in some cases. On the other hand, analyzing the spatial distribution of air inclusions indicates that many air bubbles completely expire before the nucleation due to the gas outflow toward the coexisting hydrates, resulting in a decrease in the total number concentration of air inclusions from the midpoint to the bottom of the transition zone (850-1200 m) (Ohno and others, 2004). To sum up, a series of observations suggests that the heterogeneous hydrate nucleation outside air bubbles, normal bubble-to-hydrate conversion (with the help of micro-inclusions in some cases) and subsequent diffusive transport of air molecules from bubbles to hydrates take place in the ice sheet. A combination of these processes causes the complicated redistribution of air components in the ice matrix.

Hondoh and Uchida (1992) discussed the hydrate nucleation on ice surfaces, based on homogeneous nucleation theory (discussion can also be found in Uchida and Hondoh, 2000). They estimated that the energy barrier of the nucleation and the critical size of a nucleus under polar icesheet conditions are several hundred electron volts and tens of nanometers, respectively. Since these values are too large to explain the actual occurrence of hydrates in polar ice, they concluded that particular sites which provide a lowenergy barrier for the clathration must be considered.

In general, faulty ice matrix (defects) can induce hydrate nucleation since dangling bonds facilitate rearrangement of water molecules from the ice to clathrate structures (Kuhs and others, 2000). For example, Jin and others (2008) performed in situ observations of Xe hydrate growth on polycrystalline ice with X-ray computer tomography. They reported that hydrate nucleation often occurred at ice grain boundaries exposed to the gas phase (grooves). In that sense, air bubbles in the polar ice are suitable for hydrate formation, because most air bubbles are in contact with ice grain boundaries (Ohno and others, 2004), and their walls, effectively, are 'large-scale ice defects'. However, our observations indicate that a significant amount of hydrate can nucleate outside the bubbles (Ohno and others, 2004), suggesting the presence of more effective nucleation sites.

Another aspect for gas hydrate nucleation is the collection of gas molecules, which is essential to stabilize clathrate cages. S. Kipfstuhl and others (unpublished information) reported that micro-bubbles start to form on micro-inclusions in relaxing ice cores. The ice matrix is supersaturated with dissolved gases during relaxation. Micro-bubbles that appear after core retrieval are considered to form due to the supersaturation of gas molecules in the ice matrix. If micro-inclusions work as nucleation sites for micro-bubbles, it means that micro-inclusions can adsorb gas molecules effectively for the hydrate nucleation. We note that the Dome Fuji ice core examined here has been stored at a low temperature $\left(\sim-50^{\circ} \mathrm{C}\right)$ to avoid formation of micro-bubbles. Consequently, we observed only a few micro-bubbles in studied ice samples.

Results of this work indicate that micro-inclusions are the nucleation sites for hydrate nucleation. We consider that surfaces of some micro-inclusions work as a template of clathrate structures and also as a good adsorbent of gas molecules. Analysis of micro-inclusions inside hydrate with micro-Raman spectroscopy and a scanning electron microscope (energy-dispersive X-ray spectroscopy), currently underway, will reveal the salt structures and components essential for the heterogeneous hydrate nucleation and will provide a clue to the detailed mechanism of the nucleation.

Finally, our findings may have important implications for the interpretation of high-resolution gas records obtained from polar ice cores. The probability of nucleation often has a distribution characterized by a striped pattern as previously reported for the Dome Fuji core (Ohno and others, 2004). Faria and others (2010) have observed a layered bubble-hydrate conversion in the EPICA-DML (Dronning Maud Land, Antarctica) ice core. We argue that this secondary layering of air inclusions is probably caused by a sedimentary layering of micro-inclusions. If hydrates were nucleating uniformly in ice, the original distribution of air content would remain unchanged despite the mass transfer between bubbles and hydrates. However, the non-uniform distribution of a hydrate nucleation rate may provoke a macroscopic gas flux from a layer where relatively many bubbles remain, to a layer in which the bubble-to-hydrate transition proceeds faster, resulting in significant redistribution of air constituents. Anomalous depth profiles of gas compositions, probably due to strong fractionations between the bubbly and hydrate-rich layers, were first reported by Huber and Leuenberger (2004). They performed highresolution measurements of the isotope and elemental ratios of air in the Greenland Icecore Project (GRIP) ice core and found that the elemental ratios (e.g. $\mathrm{Ar} / \mathrm{O}_{2}$ and $\mathrm{O}_{2} / \mathrm{N}_{2}$ ) show roughly annual (cm-scale) variations at depths where air bubbles convert into hydrates, although such variations were not observed at shallower depths. Recently, similar anomalies in $\mathrm{CO}_{2}$ and $\mathrm{O}_{2} / \mathrm{N}_{2}$ variations in and just below the bubble-hydrate transition zone have been found in the EPICA-DML core (Lüthi and others, 2010).

We are now developing a global bubble-to-hydrate model incorporating the processes described above. We expect that the new model based on the new findings will allow more accurate evaluation of the modifications of climate signals that occur in the properties of air inclusions during the transition.

\section{ACKNOWLEDGEMENTS}

We thank all participants for fieldwork, ice sampling and logistical support. This research is supported by a Grant-inAid for Creative Scientific Research, Japan. We thank S. Kipfstuhl and an anonymous reviewer for valuable comments.

\section{REFERENCES}

Alley, R.B., J.H. Perepezko and C.R. Bentley. 1986. Grain growth in polar ice: I. Theory. J. Glaciol., 32(112), 415-424.

Barkov, N.I. and V.Y. Lipenkov. 1984. Kolichestvennaya kharakteristika struktury I'da do glubiny $1400 \mathrm{~m} v$ rayone stantsii Vostok v Antarktide [Numerical characteristics of ice structure down to a depth of $1400 \mathrm{~m}$ in the region of Vostok station, Antarctica]. Mater. Glyatsiol. Issled. 51, 178-186. [In Russian with English summary.]

Dome-F Deep Coring Group. 1998. Deep ice-core drilling at Dome Fuji and glaciological studies in east Dronning Maud Land, Antarctica. Ann. Glaciol., 27, 333-337. 
Faria, S.H., J. Freitag and S. Kipfstuhl. 2010. Polar ice structure and the integrity of ice-core paleoclimate records. Quat. Sci. Rev., 29(1-2), 338-351.

Hondoh, T. and T. Uchida. 1992. Formation process of clathrate airhydrate crystals in polar ice sheets. Low Temp. Sci., Ser. A 51, 197-212. [In Japanese with English summary.]

Hondoh, T., H. Shoji, O. Watanabe, A.N. Salamatin and V.Y. Lipenkov. 2002. Depth-age and temperature prediction at Dome Fuji station, East Antarctica. Ann. Glaciol., 35, 384-390.

Huber, C. and M. Leuenberger. 2004. Measurements of isotope and elemental ratios of air from polar ice with a new on-line extraction method. Geochem. Geophys. Geosyst., 5(Q10), Q10002. (10.1029/2004GC000766.)

Igarashi, M., N. Kanamori and O. Watanabe. 1998. Analytical method for small amount of polar snow and ice samples by ion chromatography. Antarct. Rec., 42(1), 64-80. [In Japanese with English summary.]

Ikeda, T. and 7 others. 1999. Extreme fractionation of gases caused by formation of clathrate hydrates in Vostok Antarctic ice. Geophys. Res. Lett., 26(1), 91-94.

Ikeda-Fukazawa, T., T. Hondoh, T. Fukumura, H. Fukazawa and S. Mae. 2001. Variation in $\mathrm{N}_{2} / \mathrm{O}_{2}$ ratio of occluded air in Dome Fuji antarctic ice. J. Geophys. Res., 106(D16), 17,799-17,810.

Jin, Y.K., H. Oyama, J. Nagao, T. Ebinuma and H. Narita. 2008. Observation of Xe gas hydrate formation on ice by X-ray imaging and in situ near-infrared measurement. In Eglezos, P. and J. Ripmeester, eds. Proceedings of the 6th International Conference on Gas Hydrates, 6-10 July 2008, Vancouver, British Columbia, Canada, P099. CD-ROM.

Kawamura, K. and 17 others. 2007. Northern Hemisphere forcing of climatic cycles in Antarctica over the past 360,000 years. Nature, 448(7156), 912-916.

Kipfstuhl, S., F. Pauer, W.F. Kuhs and H. Shoji. 2001. Air bubbles and clathrate hydrates in the transition zone of the NGRIP deep ice core. Geophys. Res. Lett., 28(4), 591-594.

Kuhs, W.F., A. Klapproth and B. Chazallon. 2000. Chemical physics of air clathrate hydrates. In Hondoh, T., ed. Physics of ice core records. Sapporo, Hokkaido University Press, 373-392.

Lipenkov, V.Ya. 2000. Air bubbles and air-hydrate crystals in the Vostok ice core. In Hondoh, T., ed. Physics of ice core records. Sapporo, Hokkaido University Press, 327-358.

Lüthi, D. and 10 others. 2008. High-resolution carbon dioxide concentration record 650,000-800,000 years before present. Nature, 453(7193), 379-382.
Lüthi, D. and 10 others. 2010. $\mathrm{CO}_{2}$ and $\mathrm{O}_{2} / \mathrm{N}_{2}$ variations in and just below the bubble-clathrate transformation zone of Antarctic ice cores. Earth Planet. Sci. Lett. 297(1-2), 226-233.

Nakahara, J., Y. Shigesato, A. Higashi, T. Hondoh and C.C. Langway, Jr. 1988. Raman spectra of natural clathrates in deep ice cores. Philos. Mag. B, 57(3), 421-430.

Narita, H. and 8 others. 1999. Characteristics of air bubbles and hydrates in the Dome Fuji ice core, Antarctica. Ann. Glaciol., 29, 207-210.

Ohno, H., V.Ya. Lipenkov and T. Hondoh. 2004. Air bubble to clathrate hydrate transformation in polar ice sheets: a reconsideration based on the new data from Dome Fuji ice core. Geophys. Res. Lett., 31(L21), L21401. (10.1029/2004GL021151.)

Ohno, H., A. Igarashi and T. Hondoh. 2005. Salt inclusions in polar ice core, location and chemical form of water-soluble impurities. Earth Planet. Sci. Lett., 232(1-2), 171-178.

Pauer, F., J. Kipfstuhl, W.F. Kuhs and H. Shoji. 1999. Air clathrate crystals from the GRIP deep ice core: a number-, size- and shape-distribution study. J. Glaciol., 45(149), 22-30.

Salamatin, A.N., T. Hondoh, T. Uchida and V.Y. Lipenkov. 1998. Post-nucleation conversion of an air bubble to clathrate airhydrate crystal in ice. J. Cryst. Growth, 193(1-2), 197-218.

Salamatin, A.N., V.Ya. Lipenkov and T. Hondoh. 2003. Airhydrate crystal growth in polar ice. J. Cryst. Growth, 257(3-4), 412-426.

Shimada, W. and T. Hondoh. 2004. In situ observation of the transformation from air bubbles to air clathrate hydrate crystals using a Mizuho ice core. J. Cryst. Growth, 265(1-2), 309-317.

Uchida, T. and T. Hondoh. 2000. Laboratory studies on air-hydrate crystals. In Hondoh, T., ed. Physics of ice core records. Sapporo, Hokkaido University Press, 423-457.

Uchida, T., T. Hondoh, S. Mae, P. Duval and V.Y. Lipenkov. 1992. In-situ observations of growth process of clathrate air-hydrates under hydrostatic pressure. In Maeno, N. and T. Hondoh, eds. Physics and chemistry of ice. Sapporo, Hokkaido University Press, 121-125.

Uchida, T., T. Hondoh, S. Mae, V.Y. Lipenkov and P. Duval. 1994a. Air-hydrate crystals in deep ice-core samples from Vostok Station, Antarctica. J. Glaciol., 40(134), 79-86.

Uchida, T., T. Hondoh, S. Mae, P. Duval and V.Y. Lipenkov. 1994b. Effects of temperature and pressure on the transformation rate from air bubbles to air-hydrate crystals in ice sheets. Ann. Glaciol., 20, 143-147. 